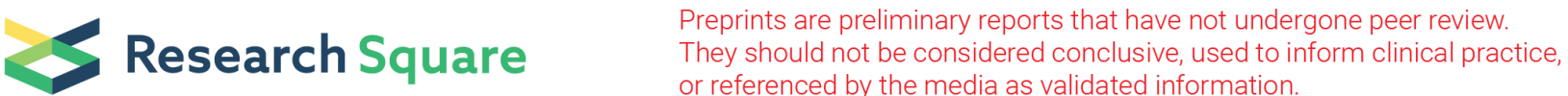 \\ Ovarian response to P4-PGF-FSH Treatment in Suffolk sheep and P4-PGF-PMSG Synchronization in Cross-bred Ewes, for IVD and ET Protocol
}

\section{STEFAN CIORNEI}

iasi uiniversity of Life Science https://orcid.org/0000-0003-3637-6184

\section{Dan DRUGOCIU}

: Life Sciences R\&D

Liliana Margareta Ciornei

lasi University of Life Science

Petru ROŞCA ( $\nabla$ petru1065@yahoo.com )

lasi University of Life Science https://orcid.org/0000-0003-0271-2581

\section{Short communication}

Keywords: hormones, Embryo Transfer, sheep, superovulation, MOET, CR

Posted Date: July 28th, 2021

DOI: https://doi.org/10.21203/rs.3.rs-711121/v1

License: (a) (1) This work is licensed under a Creative Commons Attribution 4.0 International License. Read Full License

Version of Record: A version of this preprint was published at Veterinary Medicine and Science on January 17th, 2022. See the published version at https://doi.org/10.1002/vms3.705. 


\section{Abstract}

Background

The success of an embryo transfer protocol in sheep depends on many factors, but the choice of drugs for the desired superovulation as well as the conception rate are most essential. Reproductive activity in sheep is characterized by a seasonality influenced by several factors such as photoperiod, latitude, temperature, nutrition and breed. Reproductive seasonality and nutritional condition are the main factors that influence embryo production in sheep. In sheep, some anatomical peculiarities limit the application of traditional reproductive biotechnologies used in cattle.

Methods

In vivo embryo production is often referred to as "multiple ovulation and embryo transfer" and involves ovarian superstimulation of the donor female, insemination or mating, uterine flushing for embryo recovery, and either cryopreservation or transfer of collected embryos to recipients. A total number of 60 sheep and 3 rams were included in this study, divided into 2 groups (receptors/donors). Donor Suffolk sheep were treated for superovulation using the P4-PGF-FSH protocol while the cross-bred recipients' group was synchronized with P4-PGF-PMSG.

Results

On the first day after superovulation, all ovaries had more than 5 dominant follicles, while corpora lutea were later observed in $83.3 \%$ sheep. The recovery rate was $83.3 \%$ while $72,9 \%$ embryos were transferable. Embryos were transferred directly into recipients. Fertility after 30 days was $68.57 \%$, lambing rate was $91.6 \%$, and CR $62.85 \%$. This study showed that veterinary drugs (P4, FSH, LH, PMSG, PGF) used for superovulation were capable to induce estrus and synchronize ovulation in sheep, are topical and in increasing use worldwide.

Conclusions

The aim of this study was to conclude on the effectiveness of a wider on farm in vivo embryo transfer development program in Suffolk sheep, using several veterinary hormones. The application of a multiple ovulation embryo transfer (MOET) protocol has a positive effect in the production of in vivo derived embryos in Suffolk sheep and can guarantee the success of embryo transfer activity to ewes with lower genetic merit. Our research aimed at representing a model for sheep farms for a rapid improvement of productive traits.

\section{Background}

Small ruminant ET is a well-described and yet underexploited animal breeding technology. The size of sheep, aspects of their anatomy and seasonal reproductive behavior, present challenges not common to cattle. Those considerations have not deterred serious breeders and ET practitioners in sheep producing countries [6,12].

Reproductive activity in sheep is characterized by a seasonality influenced by several factors such as photoperiod, latitude, temperature, nutrition and breed. Reproductive seasonality and nutritional condition are the main factors that influence embryo production in sheep. Nutrition has a significant effect on several aspects of reproduction including hormone production, fertilization, and early embryonic development. The relationship between sheep nutrition and embryo outcomes has not been established conclusively, but undernutrition can compromise follicles weves, luteal secretions, embryo development $[6,26]$. In sheep, some anatomical peculiarities limit the application of traditional reproductive biotechnologies used in cattle. 
Many combinations of treatments for the purposes of embryo collection and transfer are available. Estrus can be synchronized by the administration of progestogens (P4), prostaglandin F2 alpha (PGF), and pregnant mare serum gonadotrophin (PMSG) $[17,20]$.

In vivo embryo production is often referred to as "multiple ovulation and embryo transfer" (MOET) and involves ovarian superstimulation of the donor female, insemination or mating, uterine flushing for embryo recovery, and either cryopreservation or transfer of collected embryos to recipients $[13,15]$.

MOET has the potential to increase the rates of genetic improvement in sheep. However, better realization of this potential requires a higher yield of transferable embryos [15]. In vivo embryo production activities in small ruminants started as early as 1930s with the first successful report in 1934. Since then, the great majority of embryo recovery and transfer attempts were performed by surgical procedures.

Laparotomy technique allows exact counting of the number of corpora lutea and evaluation of total embryo recovery rate. However, disadvantages are the relative high cost of equipment and stress to the animal due to manipulation of the exteriorized reproductive tract [17].

The pregnancy rate following transfer of fresh embryos was satisfactory in small ruminants but not all those that were confirmed pregnant also arrived at parturition; hence, reducing the number of lambings in recipient sheep. The pregnancy rate following transfer of vitrified-thawed embryos was generally low and unsatisfactory [7].

Suffolk is considered to be a large breed of sheep, their large frame and muscular bodies make them an ideal breed for meat production; however, their wool production is good as well. Suffolk rams are commonly used as a terminal sire on cross-bred ewes due to their ability to produce off-spring with excellent growth and carcass traits.

The productivity of Romanian indigenous sheep is low, due to poor genetic merit, poor nutrition, and weak management [1]. Multiple Ovulation and Embryo Transfer (MOET) is well accepted and applied worldwide to speed up genetic gain through production of large number of lambs, reducing generation interval and utilization of superior dams $[3,16]$. The MOET program, followed by direct transfer into recipients, can reduce the cost of embryo transfer, if the estrus of donors and receptors is concomitant and the time of ovulation is synchronized at the same time [9].

The development of the small ruminant pregnancy is dependent on maternal factors in the uterine fluid biochemistry for its development. These maternal factors are critical for embryo growth, and the importance of uterine gland secretions has been demonstrated by the ablation of uterine gland development in the prepuberal sheep resulting in a maternal environment in which embryos fail to successfully development [11]. The uterine environment of the developing embryo is a key regulator of the timing and rate of production of endometrial fluid which modulates the luteolytic pathway to permit the maintenance of pregnancy [24]. Progesterone is one of the principal regulators of the endometrium during early pregnancy $[22,26]$. Embryonic mortality due to a poor uterine environment is up to 13 to $15 \%$ for multiparus compared with $3 \%$ in primiparous $[4,23]$. Several progesterone-independent and associated factors also influence embryo growth and survival, including nutrition, BCS, and metabolic state of the animal [20, 22].

Recently, extracellular vesicles (EVs) have been identified as one of the main components of the oviductal fluid in different species and proposed as mediators of gamete/embryo interactions leading to successful pregnancy [2, 19].

This study sought to evaluate the ovarian response to an original superovulation protocol (SOP) in Suffolk sheep that were previously acclimatized in Romania, the embryo recovery rate (RR), in vivo embryo production (IVD) and conception rate (CR) after transfer in cross bred recipients. We start from the hypothesis that the ovarian response is 
similar to sheep subjected to a well-established treatment, and we want to follow to what extent the ovarian reaction, embryo production and gestation rate is applicable to acclimatized meat breeds. Our research aimed at representing a model for sheep farms with low genetic background that wish for a rapid improvement of productive traits.

\section{Methods}

The present study was conducted during normal breeding season (autumn) in the N-Eastern region of Romania.

An initial number of 60 ewes and 3 rams were included in this study. The females were divided into 2 groups: Group 1

- donors' group (10 Suffolk sheep with superior genetics) and Group 2 - recipients' group (50 local crossbred sheep).

\section{Donors management}

For this experiment, 10 Suffolk ewes were initially selected, to be included in the embryo transfer protocol. Following offspring evaluation and a complete clinical and gynecological examination, performed according to embryo donor's selection criteria (IETS manual 2020), only 6 ewes $(60 \%, 6 / 10)$, aged $2.5-5$ years-old, were subjected to superovulation (SOP).

One month before the beginning of the study, each ewe was subjected again to general physical examination and deworming. The epidemiological health record of the farm was in accordance with the official regulations.

The ewes were kept on a natural pasture from 06:30 to 18:00 $\mathrm{h}$ and were housed in outdoor pens overnights. Water and a mineral supplement were available ad libitum. The management of the farm did not change throughout the whole experimental period.

\section{SOP treatment}

The 6 Suffolk sheep were superovulated using a P4-FSH-PGF protocol (figure no 1). The SOP method consisted on the administration of intravaginal sponges containing $20 \mathrm{mg}$ fluorogestone acetate (Chronogest ${ }^{\circledR}$, MDS, Holland) for 12 days, combined with 500 IU FSH:LH (Pluset ${ }^{\circledR}$, Calier, Spain) in decreasing doses, according to the manufacturer's instructions, during the last 4 days, and a PGF analogue, cloprostenol (Estrumate $\left.{ }^{\circledR}, \mathrm{MDS}, \mathrm{Holland}\right), 125 \mu \mathrm{g}$, IM on day 11.

\section{Ultrasound monitoring}

The ovarian response of donor ewes to follicular stimulation treatment was monitored by transrectal ultrasonography (Honda HS-1600V®, Japan ultrasound scanner equipped with 3,5 - $5 \mathrm{MHz}$ transducer), the probe was placed in the rectum with the transducer orientated perpendicularly to the abdomen wall. When the urinary bladder was surpassed and the uterine horns were located, the probe was rotated laterally $90^{\circ}$ clockwise and $180^{\circ}$ counter-clockwise to observe both ovaries and their structures [14]. Ultrasound performed in two essential moments: before estrus was detected and on the day of embryo recovery (flushing). Recipient ewes were also examined 30 days after embryo transfer (ET), for early pregnancy diagnosis (embryo survival and implantation).

\section{Recipients management}

All recipients were synchronized using a P4-PGF-PMSG protocol (figure no. 2). The ewes received a $20 \mathrm{mg}$ fluorogestone acetate (FGA) intravaginal sponge (Chronogest ${ }^{\circledR}, \mathrm{MDS}$, Holland) for 12 days, and cloprostenol equivalent to $125 \mu \mathrm{g}$ PGF2a (Estrumate, Intervet, Holland) on day 11. On day 12, when the intravaginal sponge was removed, ewes received an IM shot containing 200 IU Pregnant Mare Serum Gonadotrophin (PMSG; Folligon ${ }^{\circledR}$, 
Intervet, Holland). The dynamics of ovarian activity was monitored through ultrasound examination. The endorectal technique proved to be much more effective compared to the transabdominal one.

\section{Rams management}

Three Suffolk rams were selected for biostimulation, estrus detection and breeding. The ram with best pedigree and reproductive performance was retained for donor mounting, while the other two were used as teaser rams. About a month before, they were separated and fed a high-energy ratio as well as vitamin-mineral supplements. In order to stimulate libido and spermatogenesis, a dose of GnRH agonist - $10.5 \mu \mathrm{g}$ busereline acetate (Receptal, MDS, Holland) was administered. Seven days before starting the protocol, an andrological examination was performed including sperm collection and qualitative evaluation of the ejaculate.

\section{Estrus management}

In order to improve estrous behavior and ovulation (inducing the male effect), the presence of teaser males was permitted from the moment of intravaginal device removal until $60 \mathrm{~h}$ later. This was also required for estrus detection (which occurred 36 to $60 \mathrm{~h}$ after FGA sponge removal). Upon estrus detection, 3 mounts were allowed at 12 hours interval, in the donor group, using the designated ram. The other two teaser rams detected the ovulatory moment in the recipient group. In order to ensure accurate donors' and recipients' synchronization, the recipient ewes which accepted rams' mounting in the same time as donors (or within an interval of 6-12 hours) were identified.

\section{Embryo Collection}

Seven days after mounting, the embryos were recovered by the laparoscopic surgical technique [4].

Donors were not allowed to eat for $18 \mathrm{~h}$ before surgery, while water removal was done $12 \mathrm{~h}$ before surgery. Donors were premedicated with a suitable sedative, antibiotic, and nonsteroidal anti-inflammatory, given well in advance of any procedure. The ewe was placed in dorsal recumbency on a specially designed laparoscopy cradle. Both ovaries were examined by ultrasound and laparoscopy. If a superovulatory response of $\geq 3$ well-developed corpora lutea (CL) was recorded, the donor was considered acceptable for embryo collection. Uterine flushing was performed using Vigro complete flush $^{\text {TM }}$ (Vetoquinol, USA) a two-way catheter (Vortech 14Ch) and a filter (EmSafe Filter).

\section{Evaluation of In Vivo-Derived sheep embryos}

Examination of the recovered flushing fluid was performed under a 20-80X magnification, using a stereomicroscope. Criteria for embryo evaluation and classification were the same as for bovine embryos and as described in the IETS Manual (4 ed.2010). The main difference in sheep embryos is that development occurs faster and blastocyst stages are attained 0.5 to $1.0 \mathrm{~d}$ earlier than in bovine embryos. Embryo quality was evaluated under a numerical combination code based on morphological integrity of embryos (Manual of the International Embryo Technology Society, 5th Edition) ranging from Code 1 to 5, from excellent or good to bad or degenerated embryos [16]. The excellent and good embryos were loaded into the Tomcat catheter in a small volume of holding medium between two air bubbles positioned on both sides of the embryo.

\section{Embryo Transfer Procedure}

Embryo transfer in the recipients' group was performed by a minimally invasive surgical method using laparoscopy, which allows the placement of embryos directly into the cranial portion of the uterine horn. This is the standard method used worldwide [16]. The embryo was placed in the ipsilateral horn of the good quality CL. 


\section{Results}

All superovulated ewes responded to stimulation and new follicular waves were identified on the ovaries, by transrectal ultrasonography. On the first day after donors' SOP treatment, all ovaries had more than 5 follicles (Fig. 3.A), with no significant differences between ewes and ovaries. Nevertheless, 7 days after estrus, corpora lutea (CL) were only observed in $5 / 6$ ewes (83.3\% had ovulated).

At the time of abdominal laparotomy, an average of 9.1 CL / sheep were identified. The distribution within the six donors was: $0,11,12,15,9,8$. The total number of CL observed was 55,29 on the right ovary and 26 on the left one. The distribution right/left of $\mathrm{CL}$ was $0 / 0,6 / 5,7 / 5,7 / 8,4 / 5,5 / 3$ (Fig. 3.B).

The total number of embryos obtained was 48 , and therefore the recovery rate (number of embryos/CL) was $83.3 \%$. The number of embryos/CL in the 6 donor ewes was $0 / 0,10 / 11,8 / 12,13 / 15,9 / 9,8 / 8$.

A total number of 35 embryos (72,9\%) were transferable. They all were excellent or good blastocysts (stage 5, 6, 7 quality 1 and 2, according to the IETS recommended codification). The unviable embryos (13/48, 27,1\%) were degenerated, unfertilized or hatched.

Generally, unless otherwise agreed, only Code 1 embryos are used for international trade of frozen embryos. Code 1 to 3 are considered as transferable embryos when used fresh. A lower pregnancy rate is obtained with Code 2 , and even lower with Code 3 embryos, which should not be frozen. Code 4 embryos are always discarded.

In our study, following synchronization, the recipients' group was monitored for 3 days after the end of treatment, for signs of estrus. If recipients' estrus was detected within a maximum of 12 hours from that of donors, we evaluated it as an adequate response. This was considered an essential condition for the transfer of embryos to the recipient ewes. When donors were in heat and were mounted by rams, 42/50 recipients showed signs of estrus (84\%). The other recipients had late estrus and were removed from our study.

Regarding the time of synchronization with the donors, $92.9 \%$ of recipients (39/42) showed estrus signs within less than 6 hours, and only $7.1 \%$ (3/42) were in heats within 6-12 hours from donor ewes (table no 1).

Table no 1. The effect of veterinary drugs on superovulation and ovulation synchronization, in the donor and recipient group, embryo production and conception rate in Suffolk sheep

\begin{tabular}{|c|c|c|c|c|c|c|c|}
\hline \multicolumn{4}{|c|}{ Donor } & \multicolumn{4}{|l|}{ Recipient } \\
\hline \multirow[b]{2}{*}{ no } & in & \multirow[b]{2}{*}{ in estrus } & \multirow[b]{2}{*}{ flushing** } & \multirow[t]{2}{*}{ in estrus } & \multicolumn{2}{|c|}{ synchronized with donors } & \multirow{2}{*}{$\begin{array}{l}\text { recived } \\
\text { embryo }\end{array}$} \\
\hline & SOP* & & & & less $6 \mathrm{~h}$ & $6-12 \mathrm{~h}$ & \\
\hline $100 \%$ & $60 \%$ & $100 \%$ & $83,30 \%$ & $84 \%$ & $92,90 \%$ & $7,10 \%$ & $89,70 \%$ \\
\hline 10 & $6 / 10$ & $6 / 6$ & $5 / 6$ & $42 / 50$ & $39 / 42$ & $3 / 42$ & $35 / 39$ \\
\hline
\end{tabular}




\begin{tabular}{|c|c|c|c|c|c|c|c|c|}
\hline \multicolumn{4}{|c|}{ Corpus Luteum (CL) } & \multicolumn{2}{|c|}{ Embryo (EMB) } & \multirow{2}{*}{$\begin{array}{l}\text { Fertility } \\
30 \text { days }\end{array}$} & \multirow[t]{2}{*}{ Lambing } & \multirow{2}{*}{$\begin{array}{l}\text { Conception } \\
\text { Rate }\end{array}$} \\
\hline & & & average & Recovery & Transferable & & & \\
\hline \multirow[t]{2}{*}{ no } & $\mathrm{L}$ & $\mathrm{R}$ & CL/sheep & & qual. I, II & $\mathrm{F} \%$ & LR\% & $\mathrm{CR} \%$ \\
\hline & & & & $87,30 \%$ & $72,50 \%$ & $68,57 \%$ & $91,60 \%$ & $62,85 \%$ \\
\hline 55 & 29 & 26 & 9,1 & $48 / 53$ & $35 / 48$ & $24 / 35$ & $22 / 24$ & $22 / 35$ \\
\hline
\end{tabular}

Embryos were transferred directly (1 embryo/synchronized recipient), thus the proportion of sheep that received an embryo was $89.7 \%$ (35/39). All recipients had one or two CL on their ovaries, which guaranteed the ovulatory effect of the treatment applied.

Fertility at 30 days was $68.57 \%$ (24/35), lambing rate (LR) was $91.6 \%(22 / 24)$, and conception rate (CR) $62.85 \%$ $(22 / 35)$.

The management and quality of recipient females are key factors in a successful embryo transfer program. The presence of males (teasers) was from intravaginal device removal to $60 \mathrm{~h}$ later and is required for detection of estrus (36 to $60 \mathrm{~h}$ ), and for inducing male effect to improve estrous behavior and ovulation.

\section{Discussion}

The development of this reproductive biotechnology in sheep has had a similar development in the past, especially in important breeds of sheep and goats (like the Suffolk breed). Small ruminant ET is a well described and yet underexploited animal breeding technology. The size of sheep and goats, aspects of their anatomy and seasonal reproductive behavior, present challenges not common to cattle.

Those considerations have not deterred serious breeders and ET practitioners in sheep and goat producing countries. The success of an ET protocol in sheep depends on many factors, but in the end, what matters is the number of embryos obtained. Recovery rate is an essential step in ET. Biotechnology of Embryo Transfer is applied to females of superior genetic and aims to increase the frequency of their genes by increasing their progeny. ET allows the transfer of embryos from superior females (donors) to recipients with low genetic value or embryo freezing for later use. Obtaining embryos is influenced by the development dynamics of the ovarian follicles, but also by their ovulation [1].

Response to superovulation: approximately $25 \%$ of programmed donors will not respond to superovulation treatments. Some never respond, some may respond on a subsequent program. If the donor responds, she may produce from 1 to over 30 embryos, with average 8 to 12 depending on the breed, time of year, condition of animal [3, $9,15]$.

The superovulatory ovarian response to our donors was $83.3 \%$, a fairly high percentage given that the medication used was long lasting and used several hormones involved in reproductive function. The result is at the upper limit of those published by other authors in similar experiments $[3,5,12,21]$. A $77.8 \%$ of females showed ovulation with a mean of 9.6 CL and 3,3 viable embryos [10].

In such an ET Direct/in vivo program, (donor flushing and embryo transfer in the same day), it is recommended that 8 to 10 recipients per donor be synchronized to ensure that at least 6 to 8 recipients will be suitable for direct embryo transfer. The number of recipients initially programmed per donor may be adjusted if there is prior information about the expectation of donor response and potential embryo yield [17]. 
An effective estrus synchronization regimen (recipient group) is expected to synchronize the estrus of the treated animals within a 12 to 24 -h period, stimulate high rates of estrus and ovulatory response, and enable the achievement of a high pregnancy rate. The most common methods used for the hormonal control of the estrus cycle in ewes include the establishment of an artificial corpus luteum (CL) function through the administration of progestogens for a certain time period, the stimulation of luteolysis by means of the administration of luteolytic agents, and the synchronization of ovulation by means of the combined administration of gonadotropin-releasing hormone (GnRH).

In this method, the function of the corpus luteum is simulated by application of analogous progesterone compounds. The release of gonadotropins is inhibited by progesterone, and, hence, the ovulation is also inhibited until progesterone is removed (figure no 2). Is applied for a group of females and withdrawn simultaneously, this will synchronize the estrus and ovulation in recipient group.

Progesterone was initially delivered for a period equal to the length of the natural luteal phase. There are various administration time protocols such as: Long-term progesterone treatments (18 to 21 days), and Short-term progesterone treatments (7 to 12 days). Therefore, it is crucial to include a luteolytic agent in combination with shortterm progesterone treatments in order to get rid of any natural corpus luteum. This technique is applicable for cycling and non-cycling ewes during the breeding and non-breeding season, but in this case, ovulation induction is required e.g. administration of 200 IU eCG.

An injection of PGF2a, or one of its analogs, during the mid-luteal phase of the estrus cycle can induce a premature $\mathrm{CL}$ regression and ewes, therefore, can be expected to exhibit estrus symptoms approximately 50 hours later.

Following the hormonal protocol in the local sheep breeds (cross breed Turcana, Țigaia) the growth of mature follicles and synchronization of estrus was induced. We consider that the veterinary drugs that were administered to recipients (P4, PGF-PMSG) provided a favorable response (estrus and ovulation synchronization) of $84 \%(42 / 50)$, Synchronization was perfect in $92.9 \%$ (39/42) of recipients in heats.

Worldwide, the number of IVDs in sheep increased in 2019, compared to 2018, 22.374 vs 17.353 (+28.8\%). Among European countries, Spain reported the highest number of IVD embryos (111), with an average of 9.25 embryos / protocol, followed by Portugal with 18 embryos, an average of 6 embryos / procedure and the UK with a number of 905 embryos and an average of 5.45 embryos / procedure. In 2019 the number of IVD embryos in N America, S America has increased, compared to 2018 reports, 8295 vs 2158 (+ 73,98\%) in N America, and 10196 vs 5239 (+ $48,62 \%$ ) in S America. In Australia there was a slight decrease in the number of IVD embryos, from 2970 in 2018 to a number of 2805 in 2019 (- 5. 56\%) [5].

These studies show that the veterinary drugs used to stimulate follicular growth, induce estrus and synchronize ovulation in sheep, are topical and in increasing use worldwide.

The superovulation of Black Suffolk ewes may be affected by the seasonal changes. Generally, the ewe's ovulation rate was higher in May, whereas the viability rate of embryos was higher in September [21]. In another similar study CR in Suffolk was 59\% [8].

Results indicate that during the late compared to peak breeding season, there is an increased incidence of fertilization failure as a possible consequence of seasonal shifts in LH secretion and (or) associated effects on follicular function. Frozen-thawed embryos produced at contrasting stages of the breeding season are equally viable in vivo but those produced during the late, as opposed to the peak breeding season have lower viability following in vitro culture [18]. 
This study sought to evaluate the ovarian response to superovulation protocol (SOP), embryo recovery rate, in vivo embryo production (IVD) in Suffolk sheep acclimatized in Romania as well as conception rate (CR) in local recipients. Results proved that the MOET protocol applied had a positive effect on the production of in vivo embryos (IVD) in Suffolk sheep and can guarantee the success of ET activity to ewes with lower genetic merit.

\section{Conclusions}

The application of reproductive biotechnologies and animal assisted reproduction technology, aim at obtaining fetuses and productions from farm animals. The optimization of the reproduction results materialized by economic efficiency is largely influenced by the choice of the most suitable method and with the use of the most efficient hormonal drugs. Medicines and application protocols are constantly being improved and only those that are validated by preliminary studies should be used, depending on the specifics of each farm and animal breed.

These studies show that veterinary drugs (P4, FSH, LH, PMSG, PGF) used to SOP induce estrus and synchronize ovulation in sheep, are topical and in increasing use worldwide. The MOET protocol applied have a positive effect in the production of in vivo embryos (IVD) in Suffolk sheep, with good results even above those published in the literature and can garantee the success of ET activity of this breed in Romania.

\section{Abbreviations}

ET - embryo transfer

P4- progesterone,

PGF- prostaglandine F2 alpha,

FSH - follicular stimulation hormone

PMSG - pregnant mare serum gonadotrophin (similar eCG)

LH - luteinizing hormone

MOET - multiple ovulation and embryo transfer

BCS - body condition score

EVs - extracellular vesicles

SOP - superovulation protocol

$\mathbf{R R}$ - recovery rate

IVD - in vivo embryo production

CR - conception rate

FGA - fluorogestone acetate

GnRH - gonadotrophin realizing hormone

CL - corpora lutea 


\section{Declarations}

\section{Ethics approval and consent to participate}

This study was approved by the lasi University of Life Sciences (IULS), Faculty of Veterinary Medicine, Bioethics committee following the EU 2010/63 and National directives Ord. 28 / 31-08-2011 and National Law 206/2004. This study was commissioned and requested by the farmer-economic agent, through the collaboration grant USAMV IASI, no 16358, 2019-2020.

\section{Consent for publication}

Not applicable for that section

\section{Availability of data and materials}

Not applicable

\section{Competing interests}

The authors declare that they have no competing interests.

\section{Funding}

This study was supported by the IASI University of Life Science (IULS), Grant with economic agent no. 16358, 20192020

\section{Authors' contributions}

Conceptualization, C.S.G; methodology, C.L.; R.P. and D.D..; software, C.S.G.; validation, D.D.; investigation, C.S.G. and R.P.; resources, R.P, and C.S.G.; writing original draft preparation, C.S.G.; writing-review and editing, C.L. and supervision, D.D. and R.P. All authors have read and agreed to the published version of the manuscript.

\section{Acknowledgments:}

We would like to thank the sheep farmer for his cooperation.

\section{Authors' information}

\section{Affiliations:}

lasi University of Life Sciences (IULS), Faculty of Veterinary Medicine, Department Clinics, Reproduction, M. Sadoveanu Alee no 8, 700489-lași, Romania

Ştefan Gregore CIORNEI, Dan DRUGOCIU, Liliana CIORNEI, Petru ROŞCA*

* Corresponding author to Petru ROȘCA,petru1065@yahoo.com

\section{References}

1. Alam MGS, Ghosh A, Mondal AK, Akbar MA. Supplementation and puberty of zebu calves of Bangladesh. The Bangladesh Veterinarian, 2001, 18 1-8. 
2. Almiñana Carmen, Bauersachs S.. 2020 Extracellular vesicles: Multi-signal messengers in the gametes/embryooviduct cross-talk, Theriogenology, Volume 150, 2020, Pages 59-69, ISSN 0093-691X, https://doi.org/10.1016/j.theriogenology.

3. Bari, F., Khalid, M., Haresign, W., Murray, a., Merrell, B. Factors affecting the 305 survival of sheep embryos after transfer within a MOET program. Theriogenology, 2003, 306 59, 1265-1275. doi:10.1016/S0093-691X(02)011627

4. Berg, D. K., Van Leeuwen, J., Beaumont, S., Berg, M., \& Pfeffer, P. L. (2010). Embryo loss in cattle between Days 7 and 16 of pregnancy. Theriogenology, 73(2), 250-260.

5. Chair V.,J., IETS Data Retrieval Committee In: Embryo Technology Newsletter, v. 38, n.4, 2020,https://www.iets.org/Portals/0/Documents/Public/Committees/DRC/IETS_Data_Retrieval_Report_2019.pdf

6. Ciornei S., Drugociu D., Rosca P., Ciornei Liliana. Poliovulatory response and embryo recovery rate in beef sheep in Romania, as apossibility for genetic development - A case report. Anim Reprod. 2020; 17(3), OPU/IVF and ET p.10,

7. Ciornei Şt.G., Roşca P., Drugociu D., - Biotechnologies of inducing oestrus in sows using PG600. Journal of Biotechnology, 2015, Volume 208, Supplement, 20 August 2015, Pages S41, FI 3,34, doi:10.1016/j.jbiotec.2015.06.117,

8. Fair S., Hanrahan J.P., Ward F., O’Meara C.M., Duffy P., Donovan A., Lonergan P., Evans A.C.O., The difference in embryo quality between Belclare and Suffolk ewes is not due to differences in oocyte quality, Theriogenology, Volume 66, Issue 2, 2006, Pages 191-197, ISSN 0093-691X, https://doi.org/10.1016/j.theriogenology.2005.11.001.

9. Ghosh S , MRI Talukder, PK Jha, MGS Alam, NS Juyena and FY Bari. Pregnancy rate in indigenous ewes by direct transfer of vitrified embryos, The Bangladesh Veterinarian, 2017, 34(1): 27 - 33.

10. González-Bulnes, A., Baird, D. T., Campbell, B. K., Cocero, M. J., García-García, R. M., Inskeep, E. K., ... \& VeigaLópez, A. (2004). Multiple factors affecting the efficiency of multiple ovulation and embryo transfer in sheep and goats. Reproduction, fertility and Development, 16(4), 421-435.

11. Gray, C. A., Burghardt, R. C., Johnson, G. A., Bazer, F. W., \& Spencer, T. E. (2002). Evidence that absence of endometrial gland secretions in uterine gland knockout ewes compromises conceptus survival and elongation. Reproduction (Cambridge, England), 124(2), 289-300.

12. HAFEZ, E.S.E. Studies on the breeding season and reproduction of the ewe. Journal of Agricultural Science, 1952, v.42, p.189-265.

13. Jie Zhu, Adel R. Moawad, Chun-Yu Wang, Hui-Feng Li, Jing-Yu Ren, Yan-Feng Dai, Advances in in vitro production of sheep embryos, International Journal of Veterinary Science and Medicine, Volume 6, Supplement, 2018, Pages S15-S26, ISSN 2314-4599, https:// doi.org/10.1016/j.ijvsm.2018.02.003.

14. Lopez-Alonso C., Encinas T., Veiga-Lopez A., Garcia-Garcia R.M., Cocero M.J., Ros J.M., McNeilly A.S., GonzalezBulnes A.. Follicular growth, endocrine response and embryo yields in sheep superovulated with FSH after pretreatment with a single short-acting dose of GnRH antagonist, Theriogenology, Volume 64, Issue 8, 2005, Pages 1833-1843, ISSN 0093-691X, https://doi.org/10.1016/j.theriogenology.2005.04.021.

15. Menchaca A, Vilarino M, Pinczak A, Kmid S, Saldana JM. P4treatment, FSH plus eCG, GnRH administration, and day 0 Protocol for MOET programmes in sheep. Theriogenology, 2009, 72 477-483.

16. Menchaca A. and Hunton J.R., Chapter 4a. SOP for Small Ruminant Embryo Technology. Part 1, In Vivo Embryo Production, IN: Manual of the International Embryo Technology Society, 2020, 5th Edition. 
17. Mircu C., coord. coordinator. Treatise on assisted reproduction (in Romanian), Ed agroprint, Timisoara, 2020, chapter 3, pages 139-168, ISBN 978-606-785-136-6

18. Mitchell LM, Dingwall WS, Mylne MJ, Hunton J, Matthews K, Gebbie FE, McCallum GJ, McEvoy TG. Season affects characteristics of the pre-ovulatory LH surge and embryo viability in superovulated ewes. Anim Reprod Sci. 2002 Dec 16;74(3-4):163-74. doi: 10.1016/s0378-4320(02)00190-2. PMID: 12417118.

19. Ng, Y. H., Rome, S., Jalabert, A., Forterre, A., Singh, H., Hincks, C. L., \& Salamonsen, L. A. (2013). Endometrial exosomes/microvesicles in the uterine microenvironment: a new paradigm for embryo-endometrial cross talk at implantation. PloS one, 8(3), e58502.

20. Roche, J. R., Burke, C. R., Meier, S., \& Walker, C. G. (2011). Nutrition× reproduction interaction in pasture-based systems: is nutrition a factor in reproductive failure?. Animal Production Science, 51(12), 1045-1066.

21. Shi JM, Yi JY, Tian XZ, Wang F, Lian ZX, Han HB, Fu JC, Lv WF, Liu GS. Effects of seasonal changes on the ovulation rate and embryo quality in superovulated Black Suffolk ewes. Neuro Endocrinol Lett. 2015; 36(4):330-6. PMID: 26454488.

22. Shorten, P. R., Ledgard, A. M., Donnison, M., Pfeffer, P. L., McDonald, R. M., \& Berg, D. K. (2018). A mathematical model of the interaction between bovine blastocyst developmental stage and progesterone-stimulated uterine factors on differential embryonic development observed on day 15 of gestation. Journal of dairy science, 101(1), 736-751.

23. Shorten, P. R., O'Connell, A. R., Demmers, K. J., Edwards, S. J., Cullen, N. G., \& Juengel, J. L. (2013). Effect of age, weight, and sire on embryo and fetal survival in sheep. Journal of Animal Science, 91(10), 4641-4653.

24. Shorten, P. R., Peterson, A. J., O’Connell, A. R., Juengel, J. L., McNatty, K. P., \& Soboleva, T. K. (2010). A mathematical model of pregnancy recognition in mammals. Journal of theoretical biology, 266(1), 62-69.

25. Vázquez M.I., Abecia J.A., Forcada F., Casao A., Effects of exogenous melatonin on in vivo embryo viability and oocyte competence of undernourished ewes after weaning during the seasonal anestrus, Theriogenology, Volume 74, Issue 4, 2010, Pages 618-626, ISSN 0093-691X, https://doi.org/10.1016/j.theriogenology.2010.03.007.

26. Zeleke Mekuriaw, Neuro-endocrine control of reproduction in sheep, EIAR-DBARC-ICARDA-ILRI (LIVES)-FAO Training on Reproduction in Sheep and Goat, 2104.

\section{Figures}

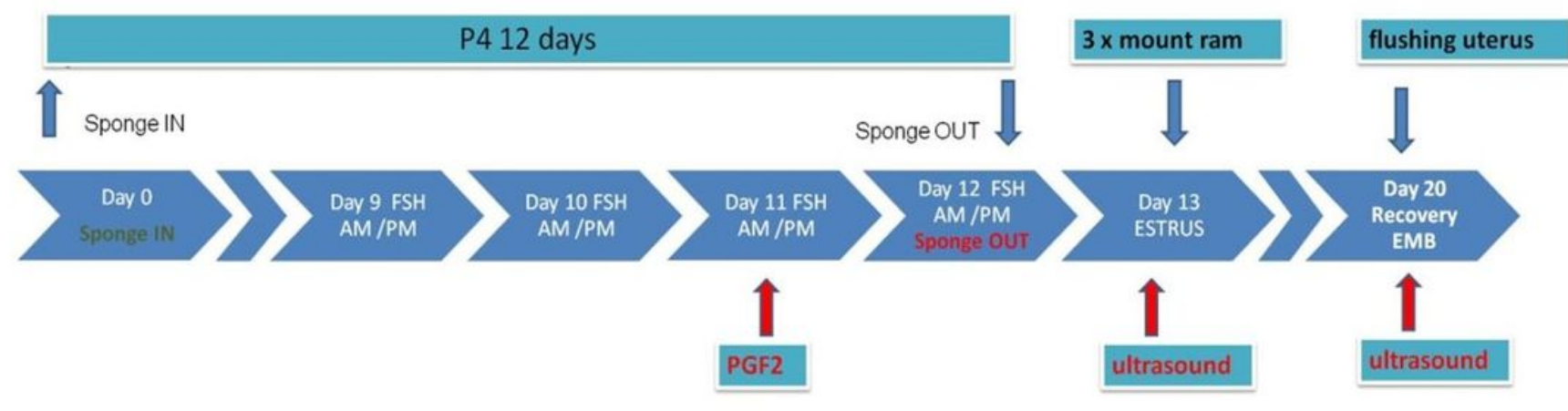

Figure 1

The associated treatment method used for ovarian activity stimulation and superovulation in donor sheep 


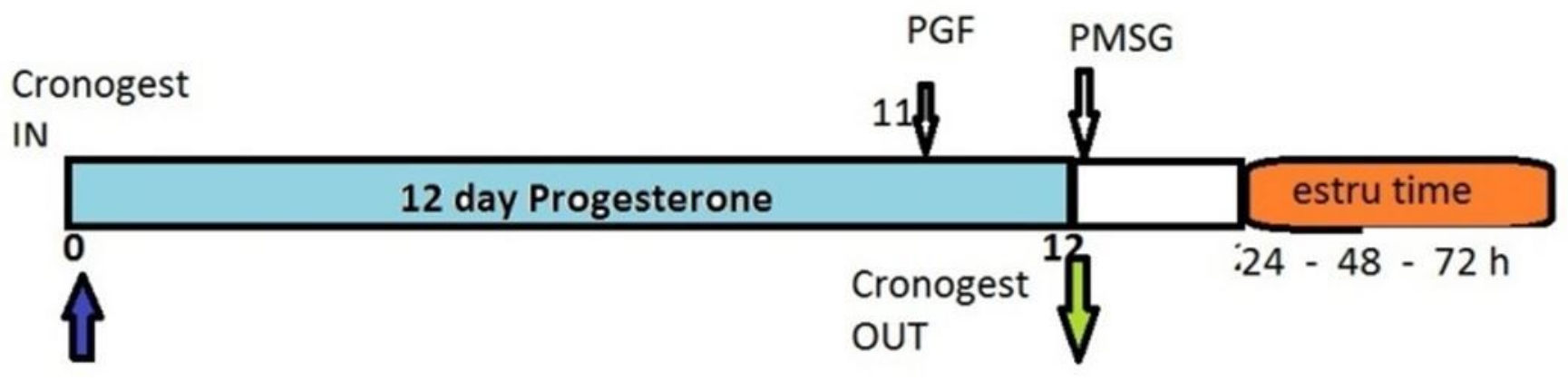

\section{Figure 2}

The combination of drugs used to induce estrus and synchronize ovulation in recipient sheep

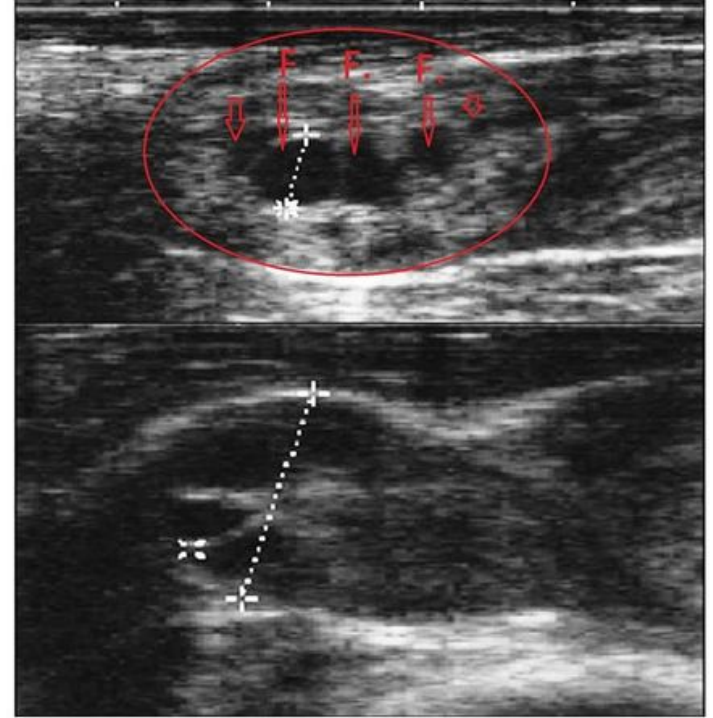

A.

Developing follicles during superovulation waves, size 3-9 mm,

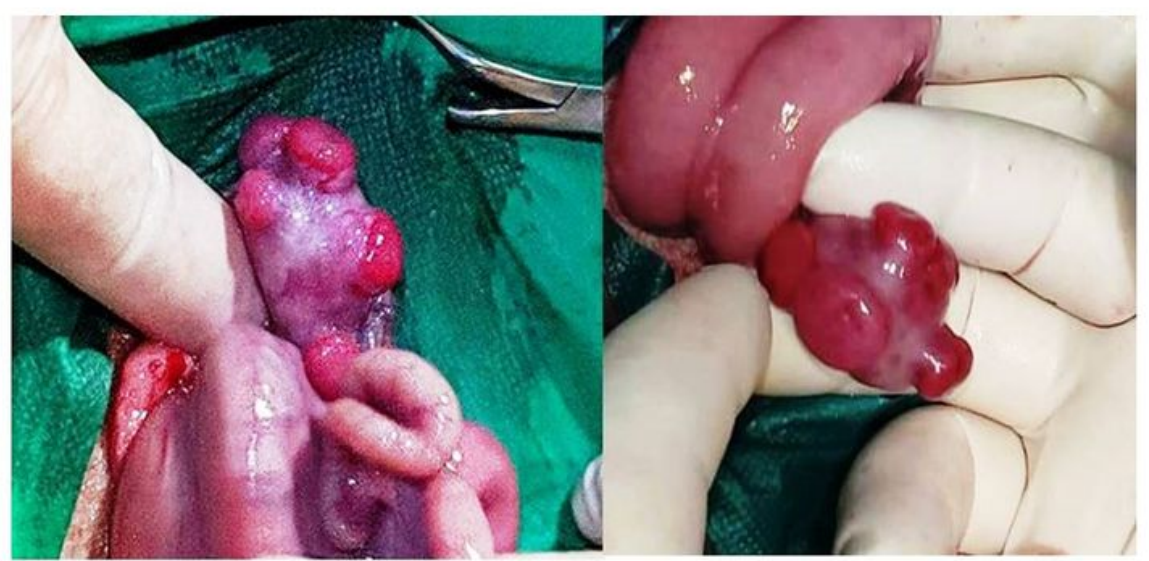

B.

Ovaries with multiple ovulatory response, more than five good CLs were observed

\section{Figure 3}

The superovulatory effect of hormone therapy induced in sheep. A. Ultrasonographic images of ovaries with follicles.

B. Marcoscopic image of ovaries with corpora lutea 